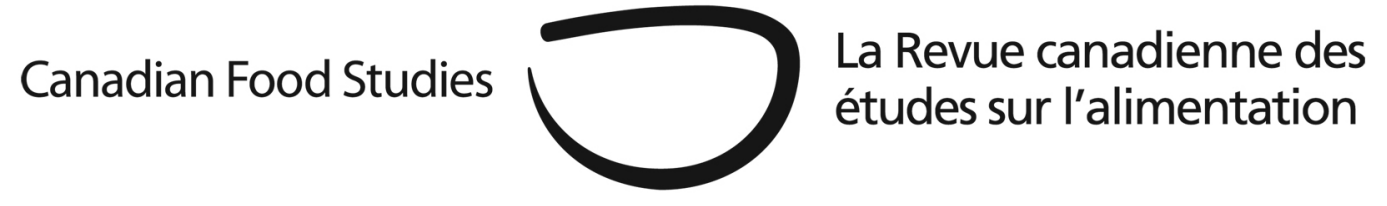

Perspective

\title{
Food discourses in Cape Breton: Community, economy, and ecological food practices
}

\author{
Erna MacLeod \\ Assistant Professor, Communication, School of Arts and Social Sciences, Cape Breton University
}

\begin{abstract}
This study examines ecological food practices on Cape Breton Island as legacies of traditional lifestyles and responses to the acceleration of global capitalism. People have many reasons for producing and consuming ecologically, ranging from health concerns to active resistance to environmental destruction and corporate control. These varying perspectives give rise to, and are reflected in, multiple discourses that shape and constrain possibilities for challenging the dominant food system. To illuminate these complexities and contextualize my investigations, I interview farmers, community organizers, restaurateurs, and policy makers, and analyze promotional literature, policies, and archival documents. I situate my observations within broader circumstances to highlight the significance of local developments for advancing similar efforts in other locations.
\end{abstract}

Keywords: ecological food, local food tourism, Cape Breton, discourse, ethnography 


\section{Introduction}

In the twenty-first century, scientific innovation and globalization have intensified our fascination with food, offering an abundance of food products and encouraging the emergence of alternative food movements, "foodie" cultures, and culinary tourism. These developments in turn have given rise to a proliferation of interpretive and critical writings that reveal divergent perspectives and points of common concern underlying changing food practices. Central issues include food security and human health; the ethical treatment of animals; the impact of industrial food production and consumption on natural environments; the significance of oppositional food strategies; the symbolic dimensions of food practices; and the economic potential of alternative food practices for local communities. Untangling these overlapping and conflicting topics reveals the complexity of food issues and the challenges facing those who promote more accountable ways of producing and consuming food.

When we examine our complex associations with food and our positions on food issues, we can accentuate food practices as discourses and as cultural performances through which we negotiate our identities and affiliations. Focusing on discourse allows me to explore food practices in terms of possibilities and constraints, including economic benefits, social connections, and healthy lifestyles; as well as time and energy demands, financial compensation, and environmental factors. The importance of sustainable food practices raises important questions: Who performs this labour and how is it financially compensated? How are products distributed and shared? What kinds of supports would make ecological practices more feasible on a broader scale? Discourse analysis is a useful way to access these varying perspectives that shape people's values and identities.

In this study, I assert that a nascent “ecological” food movement exists on Cape Breton Island, and I explore the divergent discourses accompanying this cultural and economic development. I examine the intertwining of various discourses, while disentangling multiple interests, experiences, and forms of knowledge that shape understandings of and responses to food issues in the region. Helene Shugart (2014) defines discourse as "an index of issues, values, and priorities that are resonant and exigent in a given historical moment” (p. 264). Stated simply, discourse is "a particular way of talking about and understanding the world (or an aspect of the world)” (Jorgensen \& Phillips, 2004, p. 1). Discourses embody political and ethical dimensions that engender material consequences, shaping identities, relationships, ideas, and practices. Anne Portman (2014) states that "[L]ocal food advocacy as a discourse and a practice rests on the fundamental claim that one's food choices have not just economic, but political and moral significance” (p. 4). Discursive frameworks endure through processes of resistance and social transformation yet, importantly, established frameworks change in response to human agency and historical circumstances (Barthes, 1975; Corbin, 1998; Foucault, 1977; Giroux, 2000; Martin \& Andrée, 2014).

Consumerist discourses envelop all human food practices because food consumption is fundamental to life. Yet, in the context of global capitalism, consumerist frameworks typically 
promote individual choice, low cost, and convenience, devaluing social and environmental considerations as extraneous or secondary (Guthman, 2008; Lynch \& Giles, 2013). This study argues that enlarging food discourses and framing food practices as cultural, symbolic, and ecological (as well as economic) offers possibilities for negotiating accountable and sustainable social and economic relationships. I explore the dialectical tension within consumerist discourse between "buying cheap" versus "buying local-organic."

From an economic perspective, buying cheap makes sense; however, focusing solely on economic factors elides the inherent ecological and social costs of the capitalist food system. Reintroducing these costs illuminates the ways that food practices underlie our identities, relationships, and interactions with the world. The implications of our food choices-for local economies, communities, human health, and ecological sustainability-are crucial for our survival and well-being. Consumerist discourses can be appropriated, disrupted, and redeployed to advance ecological goals.

My experiences as a Cape Breton inhabitant and cultural critic shape my investigations into the island's alternative food movement and local food tourism initiatives. Cape Breton's distinctive environmental and economic circumstances make the island an important site for examining ecological food practices. Advantages for farmers include available land, a moderate climate, and surviving natural pollinators. Disadvantages, on the other hand, include poor soil, a short growing season, and highly variable weather conditions. Fishing has always been central to the island's subsistence and economic survival, while agriculture, although less dominant, has always been important for sustaining local communities and economies. Fishing and farming, along with tourism, have become increasingly important in the twenty-first century as government and business leaders seek ways to rebuild local economies in the context of deindustrialization that has closed Cape Breton's coal-mining and steel-making industries. Examining such endeavors as they unfold is important for building sustainable food practices in this region and for understanding how collaborative organization contributes to processes of cultural and economic change. I highlight the social and environmental implications of economic developments to argue that sustainable economic strategies must respond to cultural and ecological conditions.

I begin with an examination of existing food discourses, followed by a brief historical overview of agricultural practices in Cape Breton. In subsequent sections, I explore commonalities and differences among the perspectives of multiple participants in the island's alternative food movement, including local advocates, food producers, and consumers. I additionally explore tensions between conventional and ecological farming initiatives and relations of cultural and economic power among farmers, tourists, and restaurateurs in local food tourism developments. My study suggests that ecological food practices and local food tourism initiatives offer possibilities for building economies and enriching cultural life in rural communities. 


\section{Sources of information}

To illuminate the discursive frameworks that underlie ecological food practices in Cape Breton, this study adopts a critical ethnographic approach that attends to cultural differences and power relations. Critical ethnography (Madison, 2012) brings to light inequalities and injustices to argue for empowering change. Reflections on power extend to field encounters and acknowledge the researcher's significant power to shape situations and authenticate interpretations.

My investigations are not explicitly self-reflective; however, my cultural and professional positioning inevitably shapes my analysis. In particular, my interests in rural communities, environmental issues, and animal welfare contribute to my understandings. I am not actively involved in the island's local food movement, but I am a supporter of ecological food initiatives such as farmers' markets and a consumer of local-organic produce and locally produced freerange chicken. The symbolic and political dimensions of food therefore contribute to my cultural identification.

My strategies for data collection included participant observation and in-depth, openended interviews. Participant observation consists of observing people in natural settings, participating in their activities, and offering detailed descriptions of interactions, artifacts, and events (Lofland, Snow, Anderson, \& Lofland, 2005). To understand developments in ecological food, I visited farmers' markets, restaurants, and bed-and-breakfast establishments. I also participated in food festivals, workshops, and other culinary events. My experiences in these settings enriched my understanding and analysis of ecological food practices. These locations also brought me into contact with potential interviewees, most of whom were happy to assist my research and identified additional individuals to inform my investigations.

This study includes ethnographic interviews with various stakeholders, including farmers, community organizers, government representatives, and restaurateurs. The perspectives of these participants often overlapped; for example, farmers in particular were often activists who advocated for consumer awareness and policy changes. In my analysis, I referred to these participants by their predominant and self-identified roles in local-ecological food initiatives. Our conversations provided me with access to respondents' accounts of their opinions and experiences. In analyzing interview data, I incorporated description, interpretation, and evaluation to explore the ways in which underlying power relations shape individual viewpoints and actions. My analysis begins with observation and proceeds inductively with continuous movement between observation and interpretation.

I contextualized respondents' accounts using archival documents, policy papers, tourism literature, and other transcripts related to sustainable food practices. Comparing and contrasting these texts brought to light points of commonality and disagreement that facilitate and complicate efforts to challenge mainstream food practices and establish sustainable initiatives in this region. I also consulted scholarly publications and analyzed my findings in light of ecological food initiatives in regions facing similar possibilities and constraints. Cape Breton's circumstances are, of course, particular but local conditions often encapsulate and express widely 
shared conflicts and concerns. I situated my observations within broader social and economic circumstances to highlight links between local initiatives, global developments, and possibilities for building collaborative ecological endeavours in Cape Breton and beyond.

\section{Analytical perspectives}

The following pages present my findings framed within existing debates about local-ecological food practices and local food tourism developments. Findings are categorized under five subheadings corresponding to relevant themes that emerged over the course of my research. These sections (1) identify local food discourses as they pertain to developments in Cape Breton, (2) provide a brief historical context for agricultural practices on the island, (3) illuminate conflicting discourses among advocates, producers, and consumers of local food, (4) reveal tensions between conventional and ecological food practices, and (5) examine cultural and economic power relations among farmers, tourists, and restaurateurs involved in culinary tourism endeavours. To explore these themes, I combine data from interviews with my participant observations and material from other sources.

\section{Local food discourses}

Food discourses vary within and among cultures and localities, but frameworks for understanding and debating food issues are widely shared across divergent contexts. Characteristically, discourses of sustainable food emphasize farmers' contributions and the benefits of "good food” (Shugart, 2014; Smithers, Lamarche, \& Joseph, 2008), coalescing around issues of animal rights, environmental protection, food safety, human health, and individual and local autonomy (Lynch \& Giles, 2013; Pilgeram, 2014). Local-organic food discourses, like those of industrial agriculture, foreground consumption practices, but discourses of sustainable food can constitute "oppositional strategies within consumption" (Smithers et al., 2008, p. 319) that challenge the exploitative and destructive tendencies of global capitalism (Cook, Reed, \& Twiner, 2009). As such, food movements must confront social justice issues as well as those of health and environmental sustainability (Pilgeram, 2011; 2012). Oppositional consumption strategies must support adequate incomes and manageable workloads for producers, and demand that fresh, wholesome foods are affordable and available for all cultural participants.

Food discourses intersect with those of sustainability and economic development. Participants in ecological food practices have differing political standpoints but often downplay differences to promote harmony and cooperation. Mainstream and non-dominant groups embrace overlapping discourses to advance their opposing agendas, thus the implications of ecological food are not necessarily empowering for all cultural participants (Lynch \& Giles, 2013; Martin \& Andrée, 2014, p. 191; Pilgeram, 2012; Slocum, 2007). Local food advocacy frequently reverses 
the oppositional relationship between the "natural" and "cultural," redeeming "nature" but retaining the dichotomous relationship and essentialist quality of both concepts and eliding the nuances and complexities of nature/culture and local/global (Portman, 2014, p. 27). This study explores internal differences to illuminate complexities and linkages and discern the subversive and transformative possibilities of Cape Breton's ecological food movement (Portman, 2014; Sayre, 2011).

Emphasis on consumption highlights food practices as a form of pleasure and political action to resist global capitalism (Sayre, 2011; Shugart, 2014; Starr, 2010). Consumerist discourse underscores the importance of market decisions for transforming the industrial food system and sustaining healthy bodies and communities. Highlighting consumer agency can enhance awareness of food issues and intensify demand for local products, but such frameworks are inevitably limited by their focus on individual behaviour rather than collective action to disrupt capitalist food practices. Additionally, consumers' ability to choose responsibly is compromised in capitalist cultures when corporations conceal production practices and promote corporate products as "local," "organic," and "natural.” Understanding sustainable food as a consumer movement also downplays the crucial role of food producers and the links between food practices and policies that affect resources, public health, and rural development (Sayre, 2011, p. 39).

Yet, despite inherent limits, consumerist discourses can enlarge knowledge of food politics and encourage collective responses that challenge dominant food practices. Local food initiatives become meaningful strategies for change when they engage with the interests of producers and consumers to illuminate how "agency and structure work against and through each other" in defining places and local identities (Everett, 2012, p. 552). In consumer cultures, advocates for change must learn to act within market settings, identifying contradictions and enlarging possibilities for meaningful relations (Starr, 2010, p. 486). Intersections among discourses of food, identity, sustainability, and development demonstrate that alternative food practices are converging into a powerful social movement centred on envisioning and enacting mutually beneficial social, ecological, and economic arrangements (Everett, 2012; Giampiccoli \& Kalis, 2012; Glowacki-Dudka, Murray, \& Isaacs, 2013; Sims, 2009; Starr, 2010).

All of these discourses shape local food practices and promotion in Cape Breton. Medical professionals and concerned residents underscore the health benefits of consuming local, whole, organic foods in response to significantly higher rates of heart disease, diabetes, and cancer in Cape Breton than among the overall Canadian population. Farmers, political representatives, restaurateurs, tourism operators, and community supporters promote local food as nutritious, delicious, environmentally responsible, and economically significant (with varying degrees of emphasis based on their personal and professional positioning). Proponents of local food tourism emphasize its importance as a development strategy to revitalize rural economies and offset unemployment and outmigration in the region. Implications of these strategies are complicated and economic development goals, in particular, can conflict with ecological priorities, but 
building sustainable agriculture and encouraging consumption of locally produced food products is potentially empowering for individuals and rural communities.

\section{Historical context}

Definitions of local food typically draw on the history of food production and consumption and on the symbolic significance of food traditions for particular regions or cultural groups (Bessiere, 1998; Bessiere \& Tibere, 2013; de Salvo, Hernández Mogollón, Clemente, \& Calzati, 2013). On Cape Breton Island, aboriginal people historically enjoyed abundant natural food sources, consuming large amounts of fish (e.g., salmon, eels, trout, mackerel, haddock, cod, shellfish) and meat (e.g. grouse, ducks, seals, moose, snowshoe hares) supplemented with seasonal plant foods (e.g. berries, fiddleheads, dandelion greens, nuts, and roots) (AMEC, 2013). European colonists brought their varied food traditions to the New World and adapted to local conditions through their interactions with First Nations people. They traded, fished, and hunted, and farmed beef and dairy cows, pork, poultry, eggs, potatoes, rutabagas, cabbages, and other root crops.

Although not a predominant industry in Cape Breton, agriculture has always contributed to the island's economy, but commercial food production has been limited and concentrated in particular geographical regions (for example, in Inverness and Victoria Counties) and Cape Breton has always depended on imports for much of its food supply (Beaton, 2009). Traditionally, many farms provided subsistence or supplemental incomes for families relying mainly on other types of employment to sustain their households (Beaton, 2009).

The island's economic history is based mainly on resource extraction, including fishing, forestry, and mining. During the nineteenth and early twentieth centuries, coal-mining and steel manufacture brought economic booms to industrial Cape Breton but these industries collapsed in the late twentieth century, exacerbating unemployment and outmigration. As traditional industries declined, government and business officials increasingly promoted tourism as a solution to the island's ongoing economic instability. Tourism remains an important economic strategy in the twenty-first century for creating employment, developing off-shoot industries, and generating revenue. Agriculture also remains an important economic activity: both tourism and agriculture have been identified as sectors for economic development in Cape Breton (Cape Breton Partnership, 2012).

The Nova Scotia Department of Agriculture states that farming in Cape Breton "creates significant economic activity” that contributes substantially to local communities (Statistical Profile of Cape Breton, 2011). Across Cape Breton, there are approximately 244 registered farms (7\% of NS farms), compared to 236 farms in 1996. This slight increase becomes significant when placed in the context of deep declines in the island's agricultural production during the twentieth century. By the nineteenth century, agricultural output in Cape Breton produced selfsufficiency for inhabitants along with a small surplus for export (Beaton, 1995; Howell, 1980). Farming activity peaked around 1891, then decreased sharply from 1891 to 1911 and 1941 to 1951 (Beaton, 1995, p. 7; MacKinnon, 1989, p. 7). 
Declining participation in agriculture reflects changes associated with industrialization, including importation of cheap flour and commercial foods and population migration from rural communities to the industrial region of Cape Breton for employment in coal-mining and steelmaking (Beaton, 1995; MacKinnon, 1989). Farming activities continued to decline in subsequent decades, decreasing by 19\% from 1981 to 1995 (Beaton, 1995). Growth in farm startups must also be considered in light of a 10.1\% decrease in the island's population between 1996 and 2006 (CB Partnership, 2012, p. iv). The recent emergence of new farms thus suggests renewed interest and involvement in food production.

Presently, all Cape Breton farms are relatively small operations: $45 \%$ report incomes of less than $\$ 10,000$ and $21 \%$ report farm incomes of $\$ 10,000$ to 24,999 . The majority of these farms raise beef or dairy cattle along with smaller numbers of farms producing specialty crops, field crops, poultry and eggs. ${ }^{1}$ Twenty-three percent of farms are less than 70 acres and $16 \%$ are over 400 acres. The largest category in terms of acreage accounts for farms between 180 and 239 acres (18\%) while remaining farms are smaller than 70 acres. In addition, approximately 44 farms are unregistered operations earning receipts of less than \$2499 (Statistical Profile of Cape Breton, 2011). ${ }^{2}$ These numbers indicate that participation in agriculture is increasing (despite deep declines earlier in the twentieth century) ${ }^{3}$ and that small farms contribute significantly to Cape Breton's agricultural productivity.

Cape Breton's agricultural advantages include cheap, available land, the presence of natural pollinators, and the moderating climate effects of proximity to the ocean (Smith, 2015). Climate, however, also presents challenges with generally windy conditions, exceptionally variable annual, and even daily, weather conditions, and a short growing season. Soil poses similar advantages and disadvantages: Cape Breton's soil has not been contaminated by chemical fertilizers and pesticides meaning farmers can obtain immediate organic certification for their operations, an advantage over their counterparts in regions practicing more intensive industrial agriculture. Yet participants expressed that soil quality is poor on most parts of the island and patience and intensive labour are required to establish arable farmland. Cape Breton's geographical isolation and environmental conditions thus offer unique opportunities and significant obstacles that make the island both an important place for nurturing ecological food practices and a difficult place for farmers to earn a living.

At a glance, traditional food practices in Cape Breton-primarily based on meat, salted fish, potatoes, and root vegetables - may appear mundane and perhaps unpalatable to sophisticated contemporary tastes, but the island's population and culinary traditions are diverse

\footnotetext{
${ }^{1}$ Beef farms account for 32\% of all farms in CB and dairy farms for $14 \%$. Specialty crops include ornamentals, maple syrup, honey, etc. (Statistical Profile of Cape Breton, 2011).

2 The Department of Agriculture does not distinguish between conventional and organic or ecological farms, making exact calculation of ecological practices difficult.

${ }^{3}$ During the economic boom of the early twentieth century, many rural inhabitants moved to industrial Cape Breton to work in coal mines or steel manufacturing (Morgan, 2009). In addition, advances in transportation enabled importation of cheap, commercially produced foods. The number of farms on Cape Breton Island decreased from about 2000 to 200 in approximately 60 years (DOA Representative, 19 February 2015).
} 
and the discourse of "good food" is changing. Cape Breton may be well positioned to capitalize on a resurgence of interest in grass-fed beef and dairy, pasture raised pork, free-range chicken and eggs, and fermented foods, all of which are central to traditional diets around the world (Shanahan, 2009; Teicholz, 2014). As one research participant explained:

We have a short growing season but we do grow things very well here because we don't get the high heats. This is a perfect place for livestock production; for pasture based livestock production, Cape Breton is one of the best places in the world. We just don't do it; we used to, just on this loop here there was 7 or 8 farms...

(Farmer, 23 June 2014).

In addition, fishing remains an important industry in Cape Breton despite the collapse of the Atlantic cod fishery since the 1990s. Lobster, crab, scallops, haddock, and halibut (along with other species) are well known traditional local foods that have already been marketed to attract visitors to the island (Beaton Institute, n.d.; 1981; 1988). Developing sustainable practices within these industries is an avenue for building local economies and marketing the island's heritage and culture to potential tourists.

\section{Conflicting perspectives among producers, consumers, and advocates of local food}

As food cultures and politics have gained prominence in broader realms, interest and involvement in food practices have intensified in Cape Breton. What were once the dispersed activities of individuals have coalesced in recent years in several significant developments. In 2012, a group of Cape Breton residents convened to explore collaborative ways "to create a more robust and sustainable community-based food system” (Reynolds \& Lake, 2013, p. 2). The group's efforts resulted in the establishment of a community food network to enhance public awareness, foster relationships, and promote policy changes to support local food initiatives (Reynolds \& Lake, 2013, p. 4). Members include government representatives, healthcare professionals, farmers, and members of nonprofit organizations, farmers' markets, food banks, and food-related industry. The formation of the Cape Breton Regional Municipality (CBRM) Local Food Network is a significant development in Cape Breton's ecological food movement; however, the network is concentrated in the CBRM while most farmers and local food consumers are in more rural parts of the island. Some producers and consumers have suggested that limited membership impedes the network’s significance and effectiveness. A local advocate explained:

So there's a group in Sydney that's been working at creating a local food network .... and there's some interesting discussions that come up with that of course....but there's a little back and forth because the majority of farms in Cape Breton are not from CBRM, but the majority of people are, so it's like how do we bridge that 
gap, right?... a lot of the farmers tell me it's really a struggle to sell in the CBRM too because in the rural communities people seem to be only one or two steps removed from that farming background so either they farmed as kids or their grandparents farmed... and they understand the work that goes into it so they understand if the price might be a little bit more.... And in CBRM I think it's a little bit different because people have more of an industrial background... and they don't have that direct connection and also maybe they don't understand the work that goes into the farming (Community Organizer, 21 August 2013).

Despite its limits, the local food network exemplifies the growing interest in ecological food practices, which have expanded across the island since its establishment. Subsequent developments include the creation of an island-wide food distribution hub and a local food website (cblocalfood.ca). ${ }^{4}$ These initiatives facilitate networks among producers and connections to consumers, relationships that are hampered by Cape Breton's geographically remote location and dispersed rural communities.

Local food advocates in Cape Breton-like those in many communities-are for the most part well educated and relatively affluent. Encouraging broader participation is challenging because many people perceive local, organic food as expensive and variable in terms of availability and quality (Community Organizer, 21 August 2013; Farmer 1, 25 October 2013). In many cases, the price of locally produced foods compares favourably with retail prices, so assessments of cost may reflect the value placed on convenience and predictability:

... and in a lot of cases we pay a lot less for local food but that's not the perception.... and it's all about convenience. So for example, we buy our beef at $\$ 4.25$ a pound but we buy half of a cow and we freeze it. So I don’t know how much a steak would be in the grocery store a pound but ... it's significantly more expensive so I know we really save a ton of money but when people hear, 'oh my god, you spent $\$ 700$ for a side of beef,' you know because people are so used to shopping a little bit at a time and just having that convenience of getting whatever you want when you want it and not having to store anything, put anything away (Community Organizer, 21 August 2013).

Cape Bretoners may also resist ecological food practices because food production on the island historically has been arduous and unprofitable work undertaken out of necessity, where there were few employment options and limited access to urban centres: “...most of Cape Breton, the

\footnotetext{
${ }^{4}$ The Pan Cape Breton Local Food Hub was formed in 2013. According to its website, the association is directed by the Nova Scotia Department of Agriculture, administered by Inverness County representatives, and supported and informed by food producers and consumers, including restaurants and institutions, by municipalities and federations of agriculture across Cape Breton, and by Healthy Eating Active Living (HEAL) Cape Breton, Destination Cape Breton, and the NS Department of Economic and Rural Development.
} 
industrial area of Cape Breton, escaped the farms and I think there is a thing where we came here to do industrial work and I think there's a mindset against the old-fashioned farm. A lot of people grew up on farms and all they think of is drudgery...” (Farmer, 23 June 2014). Advancements in food preservation and transportation, including roadways and construction of the Canso Causeway (1955) linking Cape Breton to mainland Nova Scotia, brought choice and abundance to Cape Breton consumers that many are hesitant to relinquish.

Importantly, however, Cape Breton's food movement is strengthened by the persistence of traditional knowledge among rural inhabitants and of practices such as hunting, fishing, and berry picking. The island appeals to a young generation of food activists who have purchased land and begun small farms in recent years (Farmer, 25 October 2013; Community Organizer, 21 August 2013; Farmer, 28 April 2015):

And there are people, a lot of people who have connections here who would like to find a way to come back so I think that's encouraging. And you've got that whole generation that's sort of the next generation of-I don't know what you want to [call them] - 'neo-hippies' or something (laughs) but there is that, there's a whole age group that are very, very interested in those old skills and whole food and real food (Farmer, 25 October 2013).

These involved cultural participants are energetic and articulate proponents of local food. Thus, while consumer demand guides sustainable food developments in many regions - in some cases creating expectations that conflict with producers' needs and values-producers are key players in Cape Breton's food movement and their dedication and knowledge enriches efforts to expand local, ecological food practices. Their stated challenge is enlarging demand for their products and simultaneously meeting the expectations of their expanding consumer base (Community Organizer, 21 August 2013).

Tensions between conventional and ecological food practices: Government, industry, and policies

Consumerist discourse, however, remains central to local food promotion in Cape Breton as food producers, small businesses, healthcare professionals, and government representatives urge community members to support local farmers and reject commercially produced and scientifically processed foods. Such strategies are important; however, my explorations reveal that various stakeholders have differing views of what constitutes "local” and "healthy" food and of why they are important. For ecological farmers, healthy foods are those produced locally through organic practices. Cape Breton's fields and forests are most easily adapted to livestock production, thus locavores often encourage consumers to buy animal products - meat, poultry, butter, eggs - that are grass-fed and free-range, and to shop at farm gates or visit farmers' markets in order to support marginalized producers and sustainable practices (Community 
Organizer, 21 August 2013; Farmer, 28 April 2015). Government representatives, healthcare professionals, and retail grocers, on the other hand, may be more concerned with changing people's diets to include less meat, more fresh fruits and vegetables, and lower fat or more "good" fats (as opposed to butter) than they are with the practices used to produce these foods. They typically define local foods as those produced in Nova Scotia without distinguishing between conventional and ecological techniques:

[The government] wants more tax revenue to go into the provincial coffers so anything we can do to make farms more profitable and have them make them more money, organic, conventional, whatever, it doesn't matter. Everything is treated equally.... I think there's a place for both and in the end it's the consumer that's going to decide (DOA Representative 1, 19 February 2015).

The Nova Scotia Department of Agriculture (DOA) establishes rules for organic certification but does not interfere with industry regulation of conventional farming. DOA representatives emphasize that policies and regulation exist to protect consumers and ensure food safety. Proponents of ecological food practices acknowledge the importance of food safety and agree that provincial funding opportunities can assist local producers; however, they criticize the bureaucratic complexity of policies and programs that encumber some farmers attempting to access financial assistance (Community Organizer 21 August 2013, Farmer, 25 October 2013, Farmer, 23 June 2015). They also insist that the distinction between organic and conventional farming is significant and that governments' inattention to the particular challenges faced by small-scale, organic producers is unhelpful and frustrating:

[A]lmost all the farms in Cape Breton really are practicing organic practices. Not a lot of them are certified organic but that again is a protest against the government because the government took over the regulating organic and now it's quite expensive. And a lot of them don't value the process anymore because you see organic stuff from China and whatever, but a lot of them are following organic practices... (Community Organizer, 21 August 2013).

Disregard for organic certification may reflect negative views of distance, scale, and authority, yet such criticism also questions the bureaucratic process that makes certification intimidating and expensive.

The predominance of small-scale organic farms is one of Cape Breton's unique advantages for enlarging ecological food practices. Yet local foods available in grocery outlets are, for the most part, conventionally grown on relatively large farms because they are distributed from a central location on mainland Nova Scotia and many local farmers cannot afford to ship their products off-island for grading and redistribution (DOA Representative, 19 February 2015; Farmer, 28 April 2015). Government involvement in agriculture offers some support to alternative food producers but ultimately constrains organic production with 
bureaucratic processes. Relations between ecological and industrial producers, on the other hand, are more contentious because conventional producers create and enforce regulations that disadvantage ecological farmers:

They oversee our production and they set the rules that we have to produce by, but we're kind of disenfranchised with them because we have no vote, we have no appeal process. Only conventional growers who hold quota have a vote so because we're a special license holder we have no say in the regulations that they make to govern us and they can change them with the stroke of a pen and they have. So it's a bit of an adversarial relationship; it has been right from the start They didn't want us to exist but there was a fellow in the Valley who was doing it and he said look, this is what I'm doing; right now it's contrary to the rules, we need to look at this because there is a demand. So they were basically told you have to allow free range so figure out a way to allow it, so it's been an uneasy (laughs) you know. You've got the conventional growers, it's not that we're a threat to their market because...[a]ll the free range chicken that's produced in Nova Scotia is less than $1 \%$ of the chicken that's consumed...but it's the perception that if people are wanting free range what's wrong with the way the conventional is grown.... So rather than take a close look at the way that they're producing their chicken and what it is that people find objectionable, it's easier just to try and quash the existence of free range. That's kind of been the tack that they've taken so it's been an uneasy relationship (Farmer, 25 October 2013).

Relations among divergent participants in local food are complex and sometimes conflicted, yet all employ concepts such as "fresh" and "local” to entice buyers and frame "buying local" as contributing to sustainable community economies.

Farmers, tourists, and restaurateurs: cultural and economic power

As demand for local, organic food grows (Farmer, 25 October 2013; Farmer, 28 April 2015), local and provincial representatives have recognized the revenue potential of expanding agriculture. Demand for sustainable local food also shapes the decisions of tourism executives in government and business, in the context of regional and national responses to global interest in food cultures and politics. As foodie cultures and alternative food movements gain global momentum, tourism promoters in Cape Breton have incorporated "local and traditional food” 
into their marketing campaigns to enhance the island's appeal as a tourist destination. ${ }^{5}$ Culinary tourism presents opportunities for showcasing local distinction, and proliferation of tourism destinations intensifies competition and encourages tourism promoters to accentuate the distinctive features of particular communities in order to attract visitors. As cultural participants engage with notions of traditional, sustainable, and local foods, they enact and express individual and collective identifications. Recognition of "authentic" and "traditional” foods can validate local identities, and the promotion of non-dominant culinary practices to cultural outsiders can encourage appreciation for local communities and their diversity (Long, 2004; Moskwa, HigginDesbiolles, \& Gifford, 2015; Sims, 2009).

Government and business efforts to support local food tourism are evident in promotional campaigns and island branding that showcase iconic foods as representations of traditional cultures and as a tourist attraction. Tourism offerings include increasing numbers of farmers' markets, food events such as strawberry festivals and lobster suppers, and locally themed menus in restaurants and bed-and-breakfasts. The Nova Scotia Tourism Agency (NSTA) promotes farmers' markets, food festivals, and locavore dining experiences in various communities across the province (novascotia.com). In May 2015, the NSTA website announced the resounding success of its first culinary workshop to teach food and tourism business operators about culinary tourism, experiential tourism, and the benefits of incorporating local food into their menus.

Cape Breton’s official tourism industry association, Destination Cape Breton Association (DCBA), describes culinary experiences as an “economic driver” for the industry in its 2015-16 Strategic Plan, defining seafood and, in particular, lobster as Cape Breton’s signature culinary tourism product (DCBA, 2015, p. 9). Public-private partnerships include Taste of Nova Scotia ${ }^{6}$ while business initiatives include festivals such as Right Some Good ${ }^{7}$. The Department of Agriculture has developed a program named Select Nova Scotia to promote local food producers, farmers' markets, retail grocers, and restaurants offering locally sourced ingredients (selectnovascotia.ca). These initiatives parallel similar strategies throughout North America and the world and likely will proliferate as localities respond to increasing global interest in cultural diversity and experiential tourism (Bessiere \& Tibere, 2013; Everett, 2012; Everett \& Slocum, 2013).

\footnotetext{
${ }^{5}$ Destination Cape Breton Association (DCBA), Cape Breton’s official tourism industry association, identifies culinary experiences as a primary focus for tourism marketing in its 2015 strategic plan and designates seafood and lobster as iconic foods. (Destination Cape Breton: Strategic Plan, www.dcba-info.com/wp/wpcontent/uploads/2015/04/ DCBA2015Plan.pdf).

${ }^{6}$ Taste of Nova Scotia is public-private marketing association formed in 1989 to assist members' business operations by promoting culinary experiences at locations across the province. Members include food producers, processers, and restaurateurs dedicated to "showcasing the best culinary experiences our province has to offer." The association operates a website that offers recipes and tips, and information about members' establishments and food events and offers and information about food events (tasteofnovascotia.com).

${ }^{7}$ Right Some Good is an annual province-wide food festival created in 2011 that features renowned chefs who host "pop-up” culinary events in various communities drawing from local cultural traditions. Cape Breton hosts three events each year in early September.
} 
Local food tourism can enrich social capital within host communities and affirm the value of local places and traditions (Dougherty, Brown, \& Green, 2013; de Salvo et al., 2013; Sims, 2009). Social capital refers to strong social networks and bonds of trust and reciprocity (Putnam, 1993), qualities enhanced through close associations between food producers and consumers and connections between community members and natural environments. Participants in Cape Breton's sustainable food movement and in culinary tourism define local food in ways that authenticate their identities and communities through their engagement with ecological food practices (Everett, 2012).

Several businesses have developed meaningful relations with local food producers that demonstrate the potential of local food tourism to benefit all participants. The Telegraph House Bed and Breakfast (telegraphhouse.baddeck.com) and the Chanterelle Inn (chanterelleinn.com) source ecological producers in the region and offer varying menus based on the seasonality and availability of ingredients. The Chanterelle Inn includes a list of suppliers on its menus, along with their locations and distance from the inn. Kiju's and Flavor 19 restaurants in Sydney also feature locally sourced ingredients for some of their fare and Flavor 19 hosts events to raise awareness of local foods and sustainable practices. In 2013, the restaurant hosted the opening dinner and weekly meetings for participants in a month-long local food challenge that now is held annually in September. During this time, Cape Breton food activist Alicia Lake follows a $100 \%$ local diet and challenges others to source $50 \%$ of their food locally. Flavor 19 offers daily specials made with local ingredients throughout the challenge.

The contributions of such initiatives extend to farmers and restaurateurs (among others) and include higher prices for local food products along with expanding social networks, enhanced social capital, and increasing economic opportunities for those involved in the food and tourism sectors (Dougherty et al., 2013). Lake describes her challenge to Cape Breton residents as a way of building community: "You're kind of building social capital, getting to know your neighbours and getting to know the different producers. You're supporting them, you're keeping money in this community, you're keeping jobs in this community, so you're really keeping people in this community at the same time as you're providing healthier food for your family" (Lake as quoted in Wadden, 2013).

Yet the benefits of local food tourism coexist with significant challenges that can impede possibilities for building social capital and establishing sustainable communities and economies (Everettt \& Slocum, 2013). Alternative food movements and tourism development therefore raise questions not only of cultural identification and but also of power relations (Urry, 1990; Long, 2004). Critics argue that tourism development delivers amenities for tourists but often provides minimal benefits to host communities, ${ }^{8}$ and that tourists typically possess greater economic and cultural capital than host cultures, which may be objectified by tourism representations. Such criticisms have merit; however, they posit tourists as passive recipients of

\footnotetext{
${ }^{8}$ John Urry (1990) and others have demonstrated that tourism typically offers seasonal, low-skilled, low-paying occupations and that tourism imagery frequently offers commodified stereotypes of host cultures.
} 
promotional strategies and elide the complexity of tourism encounters with host cultures (Schnell, 2011). Tourists are acutely aware that they are targets of tourism promotions and actively resist commodified experiences by seeking more nuanced, intimate encounters with the people and places they visit (MacCannell, 2001).

Local food tourism can respond to such desires for authenticity by enabling visitors to engage with the distinctive heritage and culture of host communities (Schnell, 2011). The proliferation of farmers' markets, CSAs, microbreweries, and restaurants featuring local cuisine therefore may signify resistance to the homogenizing tendencies of globalization (GibsonGraham, 2002) and "a conscious commitment to creating, preserving, and supporting local economic and social networks” (Schnell, 2011, p. 301).One Cape Breton farmer describes her involvement in ecological seed and food production:

I don't see how it can't be [political]... because a lot of issues around seed or even around farming are issues of control-control of the industry and food sovereignty and stuff like that.... I don't actually have a problem with corporate seed production, I think it's fair to earn a living and corporations have a right to earn a living. They don't have a right to earn an unfair living or control resources, including gene resources that belong to the people if you want to get political about it.... the government is supposed to protect people's interests, that's what they're there for, that is a good thing, and some things shouldn't be left to the marketplace to protect. Because the marketplace will only protect the marketplace and there are some things for the common good which we and our government should be protecting because they are for the common good. So in that sense, yeah it’s political (Farmer, 28 April 2015).

In addition, the class identifications and experiences of tourists and members of host communities are complex and heterogeneous. In Cape Breton and elsewhere, not all tourists are affluent and all have multiple roles, identifying as workers and community members in ways that may intersect with the standpoints of those they meet in tourism locales. Correspondingly, residents of host communities are-in various situations - consumers of places, images, and commodities. Both visitors and residents thus are cultural producers who actively shape the meaning of tourism encounters. Finally, local food tourism exemplifies "the middlebrow," a cultural sensibility that coincides with the emergence of consumer culture at the turn of the twentieth century (Rubin, 1992). Middlebrow culture educates and entertains, assuring moderate levels of refinement and erudition through the consumption of accessible ideas, artworks, and experiences. As a middlebrow practice, local food tourism offers consumers opportunities to acquire cultural capital by experiencing cultural (and in this case culinary) diversity (Radway, 
1999; Rubin, 1992). ${ }^{9}$ Critics disdain middlebrow culture for sustaining hierarchical relations by imposing the tastes, values, and practices of elites on less well-positioned cultural participants. Yet middlebrow culture also embodies a democratizing influence by disseminating cultural capital and encouraging engagement with and reflection on ideas and activities (Rubin, 1992). Local food tourism incorporates these tensions - for members of host communities and the visiting public — in its promotion of local, traditional foodways as "authentic" cultural performances and as experiences available for tourists’ consumption.

Unequal power relationships further complicate outcomes of local food tourism initiatives in relationships between food producers and restaurateurs where restaurateurs typically hold significant power over farmers in local food networks (Dougherty et al., 2013). Professional chefs often act as “opinion leaders”, promoting local food through advertising, staff recommendations, and culinary workshops, and their professional interests can conflict with those of producers when qualities such as appearance and consistency (central to consumer appeal) override commitment to sustainable production practices that require acceptance of varying ingredients and characteristics. In Cape Breton, this power imbalance plays out in restaurants and tourism establishments that use misleading language such as "we support local producers" to capitalize on the appeal of local food without sourcing menu offerings from smallscale, ecological farmers (Community Organizer, 21 August 2013). Incorporation of local food into restaurant offerings is also impeded by issues of supply and distribution, with restaurateurs emphasizing their need for low-cost, and dependably available ingredients (Inwood, Sharp, Moore, \& Stinner, 2009). Food producers, on the other hand, require adequate compensation for their labour to remain operational and costs for ecological practices typically exceed those for conventional methods. According to one ecological food advocate:

[F]or the most part, it seems like the restaurants that are using local food, it really is the upper end ...but...there are some incidences of regular restaurants claiming to use local food but we know they're really not. So then their prices seem really low and it's kind of screwing up some of the other restaurants.... But there [are] so many class issues... a lot of the more elitist restaurants want to charge a premium price and they want to appeal to this elitist class but they pressure the farmers to lower their prices.... So you want a bigger profit up here and to appeal to people who can pay over a hundred dollars a night for each person but then you want the farmer to have to...try to come up with their mortgage payment and it's infuriating, for me it's maddening. It really pisses me off (Community Organizer, 21 August 2013).

\footnotetext{
${ }^{9}$ Joan Shelley Rubin (1992) offers a detailed analysis of the authoritarian and democratic tensions within the middlebrow's reassertion of cultural standards and embrace of consumer culture. Similarly, Janice Radway (1999) examines how the Book-of-the-Month Club promoted consumption of literary works as an expression of erudition, taste and status.
} 
Effective networks require distribution hubs to connect farmers to tourism operators, ensuring access to food sources for restaurateurs and access to markets for food producers (Dougherty et al., 2013; Everett \& Slocum, 2013). Formation of the Pan-Cape Breton Local Food Hub addresses supply and distribution by establishing a collaborative association of producers and consumers to develop appropriate infrastructure for gathering, processing, and apportioning local foods. Producers welcome new markets but express concerns about pressure to reduce prices without consideration for the costs involved in producing sustainable food (Community Organizer, 21 August 2013). Economic, ecological, and identification goals may conflict as cultural participants embrace local and ecological food for their particular purposes. Ambiguous definitions of local food further obfuscate understandings and stakeholder relations (Smithers, Lamarche, \& Joseph, 2008): Does "local” refer to native foods traditionally produced and consumed within a particular geographic region? Or can local foods include those newly introduced to a region and those exported to cultural outsiders (Morris \& Buller, 2003)?

Successful local food tourism initiatives typically coalesce around foods with local historical or cultural significance-i.e. foods with unique qualities related to local climate and environmental factors (examples in Cape Breton include snowshoe hare, smelt, blueberries, fiddleheads, and chanterelle mushrooms) — or foods embodying all of these qualities (Bessiere, 1998; Bessiere \& Tibere, 2013, Everett \& Aitchison, 2008). Effective strategies therefore must integrate the divergent interests and objectives of multiple participants, and in many situations the potential benefits of promoting local food as experiential tourism remain unrealized (Dougherty et al., 2013; Everett \& Slocum, 2013). Attitudes toward food are resistant to change (Cook, Reed, \& Twiner, 2009), thus understanding the history of food practices and traditions in Cape Breton may encourage meaningful local food tourism initiatives in this region.

Finally, evidence suggests that resident populations often resist tourism development when promotional strategies conflict with local values. Resistance may be strongest in regions with economies based on resource extraction where residents' identities' are closely tied to such occupations and tourism disrupts established identifications and cultural relations (Mason \& Cheyne, 2000; Petrzelka, Krannich, \& Brehm, 2006; Reed, 2003). The tensions surrounding official and colloquial understandings of historical and cultural significance are exemplified by a Parks Canada reconstruction of a French military fortress at Louisbourg in the 1960s to offset a downturn in coal-mining (Corbin, 1996; Galt, 1987). Louisbourg residents felt little connection to the living history site and some resented the erasure of subsequent history to commemorate a fledgling French colony as a symbol of unified Canadian identity. Yet relations between the fortress and the town have improved over time and, in general, Cape Bretoners' identification with values of tradition, rurality, and hospitality has encouraged acceptance of tourism. Promotion of the island's industrial heritage in the Glace Bay Miners' Museum and the music of Men of the Deeps has fostered identification with tourism imagery among many inhabitants. 
Local food tourism may provide similar recognition of agricultural and fishing traditions. World class events such as Celtic Colours ${ }^{10}$ and enduring community endeavours such as the Louisbourg Crabfest demonstrate that tourism can validate marginalized groups by enhancing visibility in the public sphere and appreciation within the dominant culture (Boniface, 2001; Greenwood, 1989; Urry, 1990). The popularity of Cape Breton's musical heritage in the broader culture indicates that events featuring music and food traditions may be key to meaningful and profitable tourism development.

Cape Breton's ecological food movement thus is shaped by broader discourses that overlap and conflict, giving rise to tensions-particularly those between economic and ecological objectives - that constrain possibilities for enriching local communities and challenging the prevailing food system. Ecological food participants in Cape Breton face significant challenges and distinct advantages. The future of local-organic food and culinary tourism remain uncertain, but successful strategies in some communities indicate that possibilities exist for expanding such endeavours in this region.

\section{Conclusion}

Developments in Cape Breton demonstrate the entanglement of competing discourses in cultural practice and the ways in which competing discourses and unequal power relations impede efforts to build collaborative networks and enact social and economic change. This study has shown that ecological food practices, although peripheral, are becoming more prevalent across the island. Farm start-ups are typically small-scale and focused on traditional products and sustainable methods. In addition, demand for local, organic food is increasing, prompting restaurants and tourism operators to explore the cultural and economic benefits of promoting local and traditional foods. Culinary tourism has proven successful in other regions (Bessiere \& Tibere, 2013) and has potential in Cape Breton, but the island's history of economic marginalization also engenders a desire for inclusion and access to mass-produced convenience foods and global ethnic cuisine.

Paradoxically, then, rural regions such as Cape Breton that have not been fully incorporated into global capitalism have significant resources—open fields, indigenous plant life, family farms, hunting and gathering traditions, networks of social relations and barter exchange-to establish ecological economies in contexts of globalization. Yet residents of these regions may be indifferent to or ambivalent about such alternatives, aspiring instead to participate fully in global capitalism and achieve its ideals of convenience, choice, and affluence.

\footnotetext{
${ }^{10}$ Celtic Colours is an annual, island-wide, international music festival celebrated over a 9-day period in October since 1997. The highly successful festival showcases local cultures, attracts over 10,000 visitors, and features musicians from more than 24 countries.
} 
Such attitudes are understandable among marginalized populations but nonetheless raise urgent questions of social and environmental responsibility.

Increasing demand for local, sustainable food, alongside unequal power relations between producers, consumers, and policy makers can place pressure on producers to expand operations and reduce prices, creating conflicts between ecological and economic objectives. When linked to tourism, commodification of traditional foods and promotion of "fashionable" foods as "local" can be alienating for communities, provoking resistance to development strategies. Yet, as I have argued, sustainable food movements in general and local food tourism in particular present opportunities for building social capital within rural communities by enhancing collaborative networks, building shared knowledge, and bringing together people with diverse backgrounds, interests, and abilities (Dougherty et al., 2013; Porter \& McIlvaine-Newsad, 2013).

Where the divergent expectations of farmers, tourism operators, and consumers are effectively negotiated, local food tourism offers meaningful ways to build local economies, protect local environments, and enrich cultural autonomy (Glowacki-Dudka et al., 2013; Sims, 2009; Starr, 2010). Food practices are fundamental to life, intimately ecological, and profoundly social. Food discourses matter because discourse acts in the world, shaping and constraining ideas and actions. Untangling competing food discourses to encourage ecological food practices is crucially important to imagining and establishing responsible and meaningful social and economic relations in Cape Breton. In illuminating the complexity and possibilities of such relationships, this study offers insights to assist further studies into similar efforts in other locations.

\section{Future directions}

This exploratory study represents the first stage of a larger project that examines developments in ecological food on Cape Breton Island. It illuminates the complexities of food practices and, in so doing, provides a background for more deeply ethnographic investigations into various aspects of Cape Breton's alternative food movement. My current and future research will elaborate on the numerous perspectives introduced in this study, including the experiences and identities of food producers, local food tourism operators, and the many community members who support and shape their activities.

\section{Acknowledgment}

The author would like to thank Lisa Henderson, Felix Odartey-Wellington, and Carol Corbin for their encouragement and insightful comments on earlier drafts of this manuscript. 


\section{References}

Alkon, A.H. (2013). The Socio-Nature of Local-Organic Food. Antipode, 45(3), 663-680

AMEC Environment and Infrastructure (2013). A Mi’kmaq Historical and Ecological Knowledge Review of the Gaetz Brook Property. Halifax: Nova Scotia Department of Resources.

Andrée, P., Ayres, J., Bosia, M.J., \& Massicotte, M. J. (2014). Globalization and Food Sovereignty. Toronto: University of Toronto Press.

Barthes, R. (1975). The Pleasure of the Text. Translated by R. Miller. New York: Hill and Wang.

Beaton, E. (1995). Farming Immigrants to Cape Breton: Prospects and Problems. Agricultural Report. Beaton Institute, Cape Breton University.

Beaton, E. (2009). Pluractivity for Farm Families in Inverness County, Nova Scotia: The Challenge of Sustainability. In Beaton, E. (Ed.) Connecting the Dots: Social and Scientific Perspectives on Rural Life in Atlantic Canada. Sydney, NS: Cape Breton University Press: 110-140.

Beaton Institute, Cape Breton University (n.d.). Cape Breton Island: Guide to Nova Scotia’s Masterpiece, Enterprise Cape Breton Corporation: PAM 3685.

Beaton Institute, Cape Breton University (1981). Cape Breton Island Familiarization Guide, Cape Breton Tourist Association: B1 FC 3432 C36.

Beaton Institute, Cape Breton University (1988). Cape Breton Island Nova Scotia (Tourism Guide), Board of Trade, Baddeck, Cape Breton: PAM 2952.

Bessière, J. (1998). Local development and heritage: Traditional food and cuisine as tourist attractions in rural areas. Sociologia Ruralis, 38, 21-34.

Bessiere, J., \& Tibere, L. (2013). Traditional food and tourism: French tourist experience and food heritage in rural spaces. Journal of Science, Food and Agriculture, 93, 3420-3425.

Boniface, P. (2001). Dynamic Tourism: Journeying With Change. Buffalo, NY: Channel View Publications. 
Cape Breton Partnership (2012). Cape Breton Island and Mulgrave Integrative Framework for Economic Prosperity: Executive Summary. Prepared in Association with Dan White and Associates Ltd. and Hockin Cronin and Associates Ltd.

Corbin, C. (1998). Rhetoric in Postmodern America: Conversations With Michael Calvin Magee. New York: Guilford Press.

Corbin, C. (1996). Symbols of Separation: The Town of Louisbourg and the Fortress of Louisbourg. Environments, 24( 2), 15-27.

Cook, G., Reed, M., \& Twiner, A. (2009). But it's all true: Commercialism and commitment in the discourse of organic food promotion. Text and Talk, 29,(2), 159-173.

de Salvo, P., Hernández Mogollón, J.M., Clemente, E.D., \& Calzati, V. (2013). Territory, tourism and local products. The extra virgin oil's enhancement and promotion: A benchmarking Italy-Spain. Tourism and Hospitality Management, 19(1), 23-34.

Destination Cape Breton: Strategic Plan (2015). Retrieved from http://www.dcbainfo.com/wp/wp-content/uploads/2015/04/DCBA2015Plan.pdf

Dougherty, M.L., Brown, L.E., \& Green, G.P. (2013). The social architecture of local food tourism: Challenges and opportunities for community economic development. Journal of Rural Social Sciences, 28 (2), 1-27.

Everett, S. (2012). Production places or consumption spaces?: The place-making agency of food tourism in Ireland and Scotland. Tourism Geographies, 14(4), 535-554.

Everett, S., \& Aitchison C. (2008). The role of food tourism in sustaining regional identity: A case study of Cornwall, South West England. Journal of Sustainable Tourism, 16 (2), 150-167.

Everett, S., \& Slocum, S.L. (2013). Food and tourism: An effective partnership? A U.K.- based review. Journal of Sustainable Tourism, 21(6), 789-809.

Foucault, M. (1977). Discipline and Punish: The Birth of the Prison. Translated by A. Sheridan. New York: Vintage Books.

Galt, G. (1987). Making History: A reconstructed eighteenth-century fortress stands as a symbol of our national confusion about what history is truly Canadian and how to possess it. Saturday Night, 102(1), 130-132. 
Giampiccoli, A., \& Kalis, J.H. (2012). Tourism, Food, and Culture: Community-based Tourism, Local Food, and Community Development in Mpondoland. The Journal of Culture and Agriculture, 34 (2), 101-123.

Gibson-Graham, J.K. (2002). Beyond global vs. local: Economic politics outside the binary frame. In A. Herod and M. Wright (Eds.), Geographies of power: Placing scale (pp.2560). Malden, MA: Blackwell.

Giroux, H.A. (2000). Impure Acts: The Practical Politics of Cultural Studies. New York: Routledge.

Glowacki-Dudka, M., Murray, J., \& Isaacs, K.P. (2013). Examining social capital within a local food system. Community Development Journal, 48(1), 75-88.

Greenwood, D. (1989). Culture by the Pound: An Anthropological Perspective on Tourism as Cultural Commoditization. In Smith, V. (Ed.) Hosts and Guests: The Anthropology of Tourism. Philadelphia: University of Pennsylvania Press, 171-185.

Guthman, J. (2008). Neoliberalism and the making of food politics in California. Geoforum, 39, 1171-1183.

Howell, F. (1980). Agricultural Exports from Cape Breton, 1797-1865. Agricultural Report. Beaton Institute, Cape Breton University.

Inwood, S.M., Sharp, J.S., Moore, R.H., \& Stinner, D.H. (2009). Restaurant chefs and local foods: Insights drawn from application of a diffusion of innovation framework. Agriculture and Human Values, 26, 177-191.

Jorgensen, M.W., \& Phillips, L.J. (2004). Discourse Analysis as Theory and Method. London: Sage.

Lofland, J., Snow, D.A., Anderson, L., \& Lofland, L.H. (2005). Analyzing Social Settings: A Guide to Qualitative Observation and Analysis. Belmont, CA: Wadsworth.

Long, L.M. (2004). Culinary Tourism. Lexington, KY: The University Press of Kentucky.

Lynch, M., \& Giles, A. (2013). Let Them Eat Organic Cake: Discourses in sustainable food initiatives. Culture and Society, 16 (3), 479-493.

MacCannell, D. (2001). Tourist agency. Tourism Studies, 1 (1), 23-37. 
MacKinnon, R. (1989). A Century of Farming in Nova Scotia: The Geography of Agriculture, 1851-1951. Agricultural Report. Beaton Institute, Cape Breton University.

Madison, D.S. (2012). Critical Ethnography: Method, Ethics, and Performance $\left(2^{\text {nd }}\right.$ edition). New York: Sage.

Martin, S., \& Andrée, P. (2014). A Seat at the Neoliberal Table: From Food Security to Food Sovereignty in Canada. In Andrée, P., Ayres, J., Bosia, M. J., \& Masicotte, M. J. (Eds.) Globalization and Food Sovereignty. Toronto: University of Toronto Press, 173-198.

Mason, P., \& Cheyne, J. (2000). Residents’ attitudes to proposed tourism development. Annals of Tourism Research, 27(2), 391-411.

Morgan, R.J. (2009). Rise Again! The Story of Cape Breton Island, Book 2. Nova Scotia: Breton Books.

Morris, C., \& Buller, H. (2003). The local food sector: A preliminary assessment of its form and impact in Gloucestershire. British Food Journal, 105, 559-566.

Moskwa, E., Higgin-Desbiolles, F., \& Gifford, S. (2015). The Role of the Restaurateur in Sustainable Food Tourism. Journal of Sustainable Tourism, 23(1), 126-145.

Petrzelka, P., Krannich, R.S., \& Brehm, J.M. (2006). Identification with resourced based occupations and desire for tourism: Are the two necessarily inconsistent? Society and Natural Resources, 19, 693-707.

Pilgeram, R. (2012). Social sustainability and the white nuclear family: Constructions of gender, race, and class at a Northwest farmers’ Market. Race, Gender and Class, 19 (1 \& 2), 37-60.

Porter, R., \& McIlvaine-Newsad, H. (2013). Gardening in green space for environmental justice: food security, leisure, and social capital. Leisure/Loisir, 37 (4), 379-395.

Portman, A. (2014). Mother Nature Has It Right: Local Food Advocacy and the Appeal to the "Natural." Ethics and the Environment, 19, 1: 1-30.

Putnam, R.D. (1993). Making Democracy Work: Civic Traditions in Modern Italy. Princeton, NJ: Princeton University Press. 
Radway, J. (1999). A Feeling for Books: The Book-of-the-Month Club, Literary Taste and Middle-Class Desire. Chapel Hill, NC: University of North Carolina Press.

Reed, M.G. (2003). Taking stands: Gender and the sustainability of rural communities. Vancouver, Canada: UBC Press.

Reynolds, A., \& Lake, A. (15 May 2013). Overview of Previous Sessions. Establishing a Food Network for CBRM (unpublished PowerPoint Presentation).

Rubin, J.S. (1992). The Making of Middlebrow Culture. Chapel Hill, NC: University of North Carolina Press.

Sayre, L. (2011). The politics of organic farming: Populists, evangelicals, and the agriculture of the middle. Gastronomica, 11(2), 38-47.

Schnell, S.M. (2011). The local traveler: Farming food and state in state and provincial tourism guides, 1993-2008. Journal of Cultural Geography, 28(2), 281-309.

Shanahan, C. (2009). Deep Nutrition: Why Your Genes Need Traditional Food. Lawai, HI: Big Box Books.

Shugart, H.A. (2014). Food Fixations: Reconfiguring Class in Contemporary U.S. Food Discourse. Food, Culture and Society, 17(2), 261-281.

Sims, R. (2009). Food, place and authenticity: local food and the sustainable tourism experience. Journal of Sustainable Tourism, 17(3), 321-336

Slocum, R. (2007). “Whiteness, Space and Alternative Food Practice.” Geoforum, 38, 520-533.

Smithers, J., Lamarche, J., \& Joseph, A.E. (2008). Unpacking the terms of engagement with local food at the Farmers’ Market: Insights from Ontario. Journal of Rural Studies, 24, 337-350.

Starr, A. (2010). Local food: A social movement? Cultural Studies, Critical Methodologies, 10(6), 479-490.

Statistical Profile of Cape Breton (2011). Report Prepared by the Nova Scotia Department of Agriculture. Retrieved from http://nsfa-fane.ca/wp-content/uploads/2011/06/StatisticalProfile-of-Cape-Breton-County.pdf 
Teicholz, N. (2014). The Big Fat Surprise: Why Butter, Meat, and Cheese Belong in a Healthy Diet. New York: Simon \& Schuster.

Urry, J. (1990). The tourist gaze: Leisure and travel in contemporary societies. London: Sage.

Wadden, S. (29 August 2013) Baddeck woman Living la vida local. Cape Breton Post.

Interviews with Author:

Community Organizer. August 21, 2013

Farmer 1. October 25, 2013

Farmer 2. October 25, 2013

Farmer. June 23, 2014

Department of Agriculture Representative 1. February 19, 2015

Department of Agriculture Representative 2. February 19, 2015.

Farmer. April 28, 2015 